\title{
EFFECT OF YOGA TRAINING ON LIPID PROFILE IN NORMAL SUBJECTS
}

\author{
Mini K1, M. N. Vasudevan ${ }^{2}$
}

${ }^{1}$ Additional Professor, Department of Physiology, Medical College, Thrissur.

${ }_{2}^{2}$ Assistant Director, Animal Husbandry Department, Kommeri Goat Farm, Kannur.

\section{ABSTRACT}

\section{BACKGROUND}

This study was conducted to find out the basis of the effectiveness of Yoga training in the treatment of lifestyle diseases namely essential hypertension and coronary artery disease.

\section{MATERIALS AND METHODS}

The study population included the persons doing Yoga training under guidance of Satyananda Yoga Research Centre, Calicut. Blood samples were taken from the subjects after overnight fasting and the blood sugar and lipid profile estimated before and after 40 days of regular Yoga practice. The blood glucose estimation was done by glucose oxidase method. The lipid profile was estimated using cholesterol reagent kit provided by Auto span.

\section{RESULTS}

In this study, I could analyse the effect of Yoga in lowering serum total cholesterol and LDL cholesterol. But other lipid profile fractions showed no significant alterations due to Yoga training.

\section{CONCLUSION}

The daily practice of yoga can help the person to maintain a perfect homeostasis of body. It can reduce the total cholesterol and LDL cholesterol significantly. This will benefit the individual by reducing the risk factors for hypertension and coronary vascular diseases. Hence, it can be useful as a means of promoting positive health of common man. More interventional studies in patients with coronary vascular diseases by making yoga training as lifestyle change and estimating the lipid profile of the individuals after yoga are required to prove the effectiveness of yoga in coronary artery disease.

\section{KEYWORDS}

Yoga Training, Lipid Profile, Glucose Oxidase Method, Cholesterol Reagent Kit.

HOW TO CITE THIS ARTICLE: Mini K, Vasudevan MN. Effect of yoga training on lipid profile in normal subjects. J. Evolution Med. Dent. Sci. 2017;6(44):3469-3473, DOI: 10.14260/Jemds/2017/749

\section{BACKGROUND}

Yoga is a method by which the restless mind is calmed and the energy directed to constructive channels. The aim of yoga is attainment of physical, mental and spiritual health. The strain of modern life lead to mental and physical changes and when adaptation of body fails the manifestations of psychosomatic changes appear one by one. Hence, in recent times there has been an intense search for alternative measures to control psychosomatic stress disorders such as hypertension, ischaemic heart disease, peptic ulcer, diabetes mellitus, etc. The problem of modern man is to learn how to increase his stress threshold or stress competence.

There have been many studies, which throw light into effectiveness of yoga in preventing hypertension, diabetes and coronary artery diseases. In this study, an attempt is made to find out the effect of yoga training in normal subjects. Schmidt T, Wigga A, Von Zur Muhlen A, Brabant G, Wagner TO, Department of Epidemiology and Social Medicine, Hannover Medical University, Germany reveals

Financial or Other, Competing Interest: None.

Submission 27-04-2017, Peer Review 23-05-2017,

Acceptance 27-05-2017, Published 01-06-2017.

Corresponding Author:

Mini $K$,

Additional Professor,

Department of Physiology,

Government Medical College,

Thrissur, Kerala State.

E-mail: melminivasudevan@gmail.com

DOI: $10.14260 /$ jemds $/ 2017 / 749$

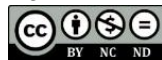

significant reduction in body mass index, serum total and LDL cholesterol, fibrinogen and blood pressure, especially in those with elevated levels. This paper shows the effect of Yoga training on the blood sugar and lipid profile in normal subjects.

\section{MATERIALS AND METHODS}

The present study was done to find out the changes taking place in lipid profile of normal subjects after a course of 40 days of yoga practice. Screening of all study subjects were done by excluding any major diseases like tuberculosis, diabetes and personal history of alcoholism and smoking. The study group included normal subjects undergoing yoga training under guidance of Sathyananda Yoga Research Centre, Calicut. 40 individuals were selected and the following pulmonary functions were done prior to and after a period of 40 days with 1 hour of Yoga practice.

\section{Study Design \\ Uncontrolled Clinical Trial}

Sample Size Calculation- The sample size could not be calculated, because this was a pioneering study related to yoga and previous studies were not available at that time. So data of all individuals were collected from the Sathyananda Yoga Research Centre, Calicut. The sample size was taken as 40 as per convenience. 


\section{Selection of Subjects}

Subjects are selected from persons free from any known disease undergoing yoga training under guidance of Sathyananda Yoga Research Centre, Calicut. They were advised to come after overnight fasting and blood samples were taken for estimation of fasting blood sugar and lipid profile.

\section{Statistical Method}

Paired ' $\mathrm{t}$ ' test was done to compare the changes in FBS and lipid profile before the beginning of yoga training and after yoga practice of 40 days.

Informed consent was obtained from the subjects at the beginning of the study. The subjects practiced the following Yoga package 1 hour daily for 40 days.

1. Vajrasana.

2. Sasankasana.

3. Katichakrasana.

4. Ardha Katichakrasana.

5. Soorya Namaskara.

6. Parswathrikonasana.

7. Parvathasana.

8. Merudandasana.

9. Kandharasana.

10. Pavanamukthasana.

11. Makarasana.

12. Bhujangasana.

13. Ardha Salabhasana.

14. Salabhasana.

15. Dhanurasana.

16. Ushtrasana.

17. Janusirshasana.

18. Paschimothanasana.

19. Vakrasana.

20. Ardhamatsendrasana.

21. Vipareethakarani Asana.

22. Sarvangasana.

23. Matsyasana.

24. Pranayamam-Nadee Sodhana.

25. Kapalabhati.

26. Yoganidra-Relaxation.

\section{Collection of Blood Samples}

Under all aseptic precautions, $7 \mathrm{~mL}$ of blood samples was drawn from antecubital vein and was collected in 2 dry bottles; $2 \mathrm{~mL}$ blood sample was collected in a bottle containing oxalate-fluoride mixture as an anticoagulant for testing blood sugar estimation. Another 5-mL blood sample was collected in a plain bottle without any anticoagulant for estimation of lipid profile. The serum used for estimation of lipid profile was obtained by centrifugation of blood sample.

Reagents for estimation of blood glucose were available in the biochemistry laboratory, Medical College, Kozhikode. Estimation of lipid profile was done using the kit provided by Autospan. HDL cholesterol and total cholesterol estimation was done using reagents in one kit and triglyceride estimation was done using a separate kit.

\section{Biochemical Analysis}

1. Fasting blood sugar estimation was done by glucose oxidase peroxidase method.

Glucose is oxidised by glucose oxidase to give gluconic acid and hydrogen peroxide. The hydrogen peroxide formed is broken down by peroxidase to water and oxygen. The latter oxidises phenol, which combines with 4 aminophenazone to give a red coloured complex. The intensity of red coloured complex is proportional to the concentration of glucose in the specimen under test. Intensity of coloured complex is measured calorimetrically at $5.15 \mathrm{~nm}$.

2. S. Total cholesterol and HDL cholesterol was done by macro method using cholesterol reagent kit.

The estimation of cholesterol involves the following enzymatic reactions-

1. Cholesterol esters -----------------> Cholesterol + Fatty acids

2. Cholesterol+ H2O- CHOD------------> Cholestenone $+\mathrm{H}_{2} \mathrm{O}_{2}$

3. $\mathrm{H}_{2} \mathrm{O}_{2}+$ Phenol+ 4AAP-----POD----------------> Quinone amine

Absorbance of Quinone amine measured at $510 \mathrm{~mm}$ (490 - $530 \mathrm{~nm})$ is proportional to cholesterol concentration in the specimen.

3. S. HDL cholesterol estimation- Low and very low density lipoproteins are precipitated by a solution containing PGE 6000 , leaving behind the HDL cholesterol is estimated in the supernatant by a series of enzymatic reactions, which are initiated by the oxidation of cholesterol to cholestenone by cholesterol oxidase accompanied by the formation of hydrogen peroxide. In a second reaction catalysed by peroxidase, 4 aminoantipyrine and phenol react with hydrogen peroxide to form red coloured quinonamine. Absorbance data at 510 (490 - 530 nm) are directly proportional to HDL cholesterol concentrations.

4. S. Triglyceride estimation-

The estimation of serum triglyceride involves the following enzymatic reactions-

Triglycerides-------LPL---------------> Glycerol + FFA

Glycerol + ATP----GK---------> Glycerol $3 \mathrm{PO}_{4}+\mathrm{ADP}$

Glycerol - $3 \mathrm{PO}_{4}+$ O2----GPO--------> DHAP + $\mathrm{H}_{2} \mathrm{O}_{2}$

$2 \mathrm{H}_{2} \mathrm{O}_{2}+$ Chromogen----POD----------> Quinoneimine dye $+4 \mathrm{H}_{2} \mathrm{O}$

- LPL- Lipoprotein lipase

- FFA- Free fatty acids

- GK-Glycerol kinase

- GPO- Glycerol $3 \mathrm{PO}_{4}$ oxidase

- POD- Peroxidase

Serum triglyceride was estimated using macro method.

5. Since direct LDL cholesterol measurement is not freely available, LDL cholesterol concentration was calculated using the following formula.

LDL cholesterol $=$ TC $-(\mathrm{TG} / 5+$ HDL cholesterol $)$.

\section{RESULTS}

Fasting blood sugar, total cholesterol, HDL cholesterol, triglyceride and LDL cholesterol were checked before and after yoga. The statistical significance of change in each parameter was obtained using paired ' $\mathrm{t}$ ' test 
' $t$ ' value was obtained using the following formula. ' $\mathrm{t}$ ' $=\mathrm{z}-/ \mathrm{Sz} \sqrt{\mathrm{n}}$

\begin{tabular}{|c|c|c|c|c|}
\hline $\begin{array}{c}\text { Increase } \\
\text { in FBS in } \\
\mathbf{m g \%}\end{array}$ & $\begin{array}{c}\text { Reduction } \\
\text { in Total } \\
\text { Cholesterol } \\
\text { in mg\% }\end{array}$ & $\begin{array}{c}\text { Reduction } \\
\text { in HDL } \\
\text { Cholesterol } \\
\text { in } \mathbf{~ m g \%}\end{array}$ & $\begin{array}{c}\text { Reduction } \\
\text { in TG in } \\
\text { mg\% }\end{array}$ & $\begin{array}{c}\text { Reduction } \\
\text { in LDL } \\
\text { Cholesterol } \\
\text { in mg\% }\end{array}$ \\
\hline $3.9 \pm 2.19$ & $38.14 \pm 9.07$ & $1.55 \pm 2.78$ & $\begin{array}{c}4.87 \pm \\
10.03\end{array}$ & $35.12 \pm 9.94$ \\
\hline $\mathrm{SD}=13.82$ & $\mathrm{SD}=57.32$ & $\mathrm{SD}=18.198$ & $\mathrm{SD}=63.36$ & $\mathrm{SD}=62.84$ \\
\hline $\mathrm{t}=1.78$ & $\mathrm{t}=4.2$ & $\mathrm{t}=0.54$ & $\mathrm{t}=0.48$ & $\mathrm{t}=3.5$ \\
\hline $\mathrm{P}>.05 \mathrm{NS}$ & $\mathrm{P}<.01 \mathrm{HS}$ & $\mathrm{P}>.05 \mathrm{NS}$ & $\mathrm{P}>.05 \mathrm{NS}$ & $\mathrm{P}<0.01 \mathrm{HS}$ \\
\hline \multicolumn{5}{|c}{ Table 1 } \\
\hline
\end{tabular}

Table 1 shows the difference in FBS and different lipid profile fractions after Yoga.

\section{Fasting Blood Sugar}

FBS was found to be in the range of $60 \mathrm{mg} \%-200 \mathrm{mg} \%$, which changed to the range of $62 \mathrm{mg} \%-200 \mathrm{mg} \%$ after yoga. The mean difference obtained after yoga in FBS is $3.9 \pm 2.19$ and the standard difference is 13.82 ; ' $\mathrm{t}$ ' value obtained is 1.78 . This is not statistically significant $(\mathrm{P}>0.05)$.

\section{Total Cholesterol}

Total cholesterol was in the range of $107.6 \mathrm{mg} \%-370 \mathrm{mg} \%$ before yoga in this study group and in the range of $110 \mathrm{mg} \%$ $248,88 \mathrm{mg} \%$ after yoga. This gives a mean reduction of 38.14 $\pm 9.07(\mathrm{SD}=57.32)$, ' $\mathrm{t}$ ' value 4.2. Reduction in total cholesterol after yoga is highly significant $(\mathrm{P}<0.01)$.

\section{HDL Cholesterol}

The S. HDL cholesterol was in the range of $12.9 \mathrm{mg} \%-79.54$ $\mathrm{mg} \%$, which changed to the range of $18.9 \mathrm{mg} \%-80.64 \mathrm{mg} \%$ after yoga. The mean difference in HDL cholesterol following yoga was $1.55 \pm 2.87$ and the SD obtained is 18.198 ; ' $t$ ' value obtained is 0.54 . The change in HDL cholesterol after yoga is not significant $(\mathrm{P}>0.05)$.

\section{S. Triglyceride}

S. Triglyceride value was noticed to be in the range of 65 $\mathrm{mg} \%$ - $190.48 \mathrm{mg} \%$, which changed to the range of 51.85 $\mathrm{mg} \%$ - $385.71 \mathrm{mg} \%$. The mean change in STG was $4.87 \pm$ 10.03, $(S D=63.36)$; ' $t$ ' value is 0.48 . The observed change after yoga in $\mathrm{S}$. triglyceride is not significant $(\mathrm{P}>.05)$.

\section{LDL Cholesterol}

The LDL cholesterol value showed highly significant $(\mathrm{P}<$ 0.01 ) reduction following yoga from the range of $27.4 \mathrm{mg} \%$ $290.5 \mathrm{mg} \%$ after yoga. Mean reduction was $35.12 \pm 9.94(\mathrm{SD}=$ 62.84), ' $\mathrm{t}$ ' value $=3.5$

The distribution of the changes in total cholesterol and LDL cholesterol among the 40 subjects is shown graphically in Fig. 1 and Fig. 2.

\begin{tabular}{|c|c|c|c|c|c|}
\hline \multicolumn{2}{|c|}{$\begin{array}{c}\text { Change in } \\
\text { Lipid } \\
\text { Profile } \\
\text { in } \mathrm{mg} \%\end{array}$} & \multirow{2}{*}{$\begin{array}{c}\text { Increase } \\
7\end{array}$} & \multirow{2}{*}{$\begin{array}{r}\text { Decrease } \\
\text { up to } 25 \\
14\end{array}$} & \multirow{2}{*}{$\begin{array}{c}\text { Decrease } \\
25 \text { to } 50\end{array}$} & \multirow{2}{*}{\begin{tabular}{|c}
$\begin{array}{c}\text { Decrease } \\
>\mathbf{5 0}\end{array}$ \\
16
\end{tabular}} \\
\hline No. of & $\begin{array}{c}\text { Total } \\
\text { Cholesterol }\end{array}$ & & & & \\
\hline Individuals & $\begin{array}{c}\text { LDL } \\
\text { Cholesterol }\end{array}$ & 7 & 13 & 6 & 14 \\
\hline \multicolumn{6}{|c|}{ Table 2} \\
\hline
\end{tabular}

Table 2 shows Change in Total cholesterol and LDL Cholesterol in relation to frequency of individuals.

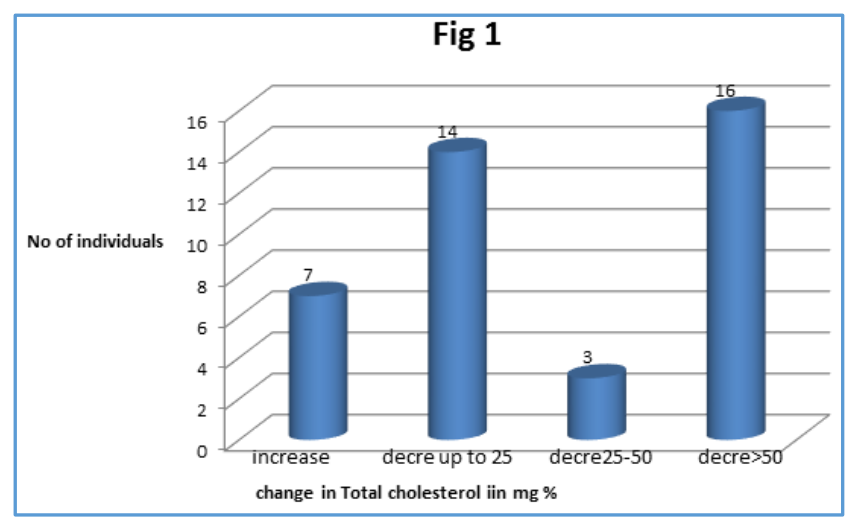

Figure 1. The Relation of Frequency of Individuals to the variation in LDL Cholesterol after Yoga in 40 Individuals

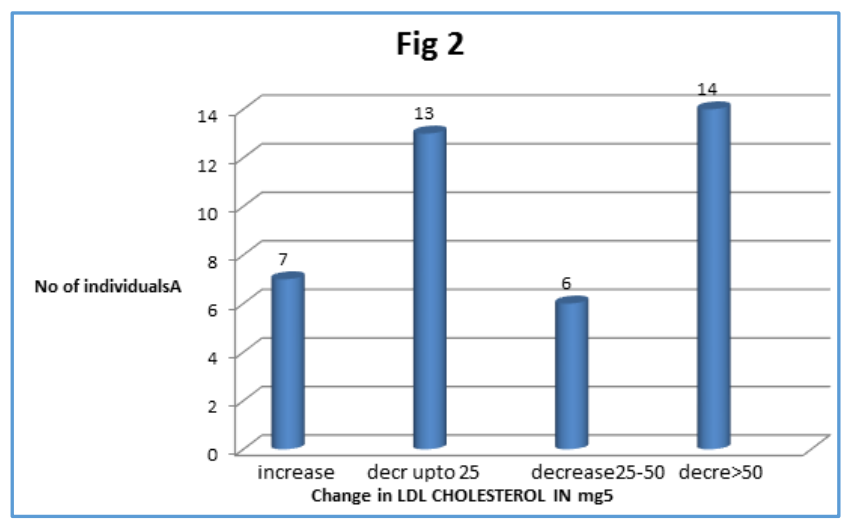

Figure 2. The Relation of Frequency of Individuals to variation in Total Cholesterol after Yoga in 40 Individuals

The decrease in Total Cholesterol was statistically significant. Even though out of 40 individuals who were undergoing yoga training 7 individuals showed an increase in total cholesterol; the rest of the subjects showed a significant reduction in Total cholesterol.

The decrease in LDL cholesterol was also statistically significant. Among the 40 subjects who has done yoga training regularly, only 7 individuals showed an increase in LDL cholesterol, the rest of the subjects showed significant reduction in LDL cholesterol.

\begin{tabular}{|c|c|c|c|c|c|}
\hline $\begin{array}{c}\text { Sl. } \\
\text { No. }\end{array}$ & $\begin{array}{c}\text { Increase } \\
\text { in FBS in } \\
\text { mg\% }\end{array}$ & $\begin{array}{c}\text { Reduction } \\
\text { in Total } \\
\text { Cholesterol } \\
\text { in mo\% }\end{array}$ & $\begin{array}{c}\text { Reduction } \\
\text { in HDL } \\
\text { Cholesterol } \\
\text { in mg\% }\end{array}$ & $\begin{array}{c}\text { Reduction } \\
\text { in TG in } \\
\text { mg\% }\end{array}$ & $\begin{array}{c}\text { Reduction } \\
\text { in LDL } \\
\text { Cholesterol } \\
\text { in mg\% }\end{array}$ \\
\hline 1 & -16 & -81.58 & 14.56 & -37.93 & -88.45 \\
\hline 2 & -4 & -12.7 & 14.06 & -4.32 & -27.54 \\
\hline 3 & 0 & 11 & -1 & -10 & 10 \\
\hline 4 & 2 & 19.95 & -6 & $-6-96$ & 24.55 \\
\hline 5 & -22 & -5.13 & $-11,11$ & 120.53 & 40.11 \\
\hline 6 & -12 & -62.33 & 24.73 & 16.87 & 41.03 \\
\hline 7 & -20 & 107.86 & 61.67 & -28.93 & 40.13 \\
\hline 8 & -16 & 101.08 & -1.16 & 33.29 & 108.81 \\
\hline 9 & 4 & 69.44 & -4.54 & -105 & 52.93 \\
\hline 10 & -8 & 60 & -3 & -31.8 & 56.66 \\
\hline 11 & 4 & 55.3 & 1.23 & -35.15 & 49.5 \\
\hline 12 & 8 & 21.74 & 8.03 & -25.94 & 8.52 \\
\hline 13 & 20 & 18.8 & 16.6 & -9.09 & 0.94 \\
\hline
\end{tabular}




\begin{tabular}{|c|c|c|c|c|c|}
\hline 14 & 19 & 42.25 & 11.3 & 81.15 & 14.72 \\
\hline 15 & 4 & 81.14 & -2.02 & 19.87 & 87.13 \\
\hline 16 & 4 & 16 & -6.1 & 9.8 & 24.16 \\
\hline 17 & 20 & 2 & -19 & -29.3 & 15.18 \\
\hline 18 & -12 & 109.61 & -34.93 & -42.81 & 135.99 \\
\hline 19 & 24 & -65.6 & 8.52 & 58.54 & -162.41 \\
\hline 20 & 20 & -56.67 & 39.93 & -9.51 & -18.54 \\
\hline 21 & 4 & 158.68 & -3.9 & -37.83 & 155.1 \\
\hline 22 & 8 & 67.55 & -23.42 & $-45-94$ & 82.68 \\
\hline 23 & 0 & 167.94 & 1.81 & 28.64 & 171.68 \\
\hline 24 & 0 & 3.25 & $-3-45$ & 15.09 & -27.14 \\
\hline 25 & 2 & $18-47$ & -0.72 & $-17-6$ & 15.67 \\
\hline 26 & 2. & -.83 & -1.53 & 0 & 13.53 \\
\hline 27 & 2 & 2.98 & -9.28 & -.4 & 9.2 \\
\hline 28 & -2 & 47.25 & -4.35 & -19.6 & -3.57 \\
\hline 29 & -2 & 58.74 & -9.22 & -15.95 & 64.8 \\
\hline 30 & 20 & -0.83 & 5.06 & 152.38 & 82.38 \\
\hline 31 & 31 & 38.61 & 5.04 & -23.81 & 28.80 \\
\hline 32 & 3 & 19.6 & -11.86 & $=13.01$ & 28.86 \\
\hline 33 & 1 & -73.28 & $=3.03$ & 150.28 & -40.25 \\
\hline 34 & 4 & 20.59 & $=5.08$ & $=6.75$ & 24.48 \\
\hline 35 & 6 & 17.96 & -3.7 & -102 & 1.26 \\
\hline 36 & 22 & 118.7 & 22.77 & 195.23 & 134.97 \\
\hline 37 & -2 & 97.29 & -1.1 & -0.02 & 97.82 \\
\hline 38 & 20 & 73.46 & 13.61 & 44.07 & 68.08 \\
\hline 39 & 34 & 106.22 & 46.8 & 93.16 & 78.01 \\
\hline 40 & -16 & 24.81 & 18.72 & -2.32 & 5.62 \\
\hline & & & & & \\
\hline
\end{tabular}

\section{Abbreviations}

FBS- Fasting Blood Sugar.

HDL- High Density Lipoprotein.

LDL- Low Density Lipoprotein.

TG- Triglyceride.

\section{DISCUSSION}

The reduction in total cholesterol, LDL cholesterol and body mass index can be explained on the basis of utilisation of excess lipids in the body during yoga practices. In addition, the vegetarian diet of yoga practitioners also probably contributed to the reduction in serum cholesterol. The nonvegetarian diet which is rich in saturated fat is omitted by the yoga group. Sarvangasana influence the thyroid gland directly. Thyroid controls metabolism of the body. Therefore, by improving the efficiency of the thyroid gland through sarvangasana one can maintain the optimum body weight. Paschimothanasana stretches and tones the spinal and hamstring muscles and the associated nerves. It loosens the hip joint and helps to remove excess fat in the abdominal region. Thus, this posture is particularly useful in reducing the body weight and in turn controlling serum total and LDL cholesterol. Reduced stress and effect on endothelial function through improved serum lipid profile is likely to have a beneficial effect on coronary artery disease.

The changes in lipid profile are mainly beneficial to cardiovascular system. Changes in heart rate, blood pressure, regional blood flow and several other cardiovascular variables have been recorded during various yogic exercises.[1] With a few months of hatha yoga training, there is an improvement in cardiovascular fitness as assessed by Harvard step test.[2]

A study by Shrikrishna Tenghe ${ }^{[3]}$ shows a fall in systolic and diastolic blood pressure after yoga. In a study conducted in sports teachers there was significant reduction in heart rate, systolic and diastolic blood pressure and body weight.
This may be correlated with decrease in lipid profile. In a study conducted by Datar SV and Kulkarni VA, there was a significant improvement in the cardiovascular efficiency measured in terms of Harvard step test fitness index, both in males and females.[4] In patients of coronary artery disease, there was a mean increase in duration of exercise, total work performance, improved left ventricular regional wall motion during peak exercise and a net change in left ventricular ejection fraction from rest to maximum exercise of $76.4 \%$. There was a mean decrease of plasma cholesterol levels and reduction in frequency of anginal episodes. ${ }^{[5]}$ In a study by SC Manchanda and R Narang at the end of one year, the yoga group showed significant improvement in the number of anginal episodes. Improved exercise capacity, decrease in body weight, serum total and LDL cholesterol and serum triglyceride levels as compared to controls. Coronary angiography repeated at one year showed that significantly more lesions regressed and less lesions progressed in yoga group. Study on the effect of selected yogic practices on the management of hypertension shows that yoga is effective as drugs in controlling the variables of hypertension. ${ }^{[6]}$ Role of yoga in management of essential hypertension shows a statistically significant fall in both mean systolic and diastolic $\mathrm{BP}$ and a significant reduction in doses of antihypertensive drugs. ${ }^{[7]}$ Blood pressure rose significantly to preshavasana levels in patients who left practicing yoga.

In a case study, it is observed that diastolic blood pressure remained within normal limits after a six-week yoga training even after discontinuing medication. ${ }^{[8]}$ The patient was subsequently returned to full flight status without recurrence of diastolic hypertension at followup 6 months later. A study conducted by Bowman A J et al shows a reduction in heart rate following yoga. In a study of the changes in cardiovascular risk factors and hormones during a comprehensive residential three-month kriya yoga training and vegetarian nutrition, substantial risk factor reduction was found. Body mass index, total serum and LDL cholesterol, fibrinogen and blood pressure were significantly reduced, especially in those with elevated levels. [9]

\section{CONCLUSION}

There was a highly significant reduction in total cholesterol and LDL cholesterol after practice of Yoga. The body mass index also showed a significant reduction after Yoga practice. There was a reduction in HDL cholesterol and triglyceride, which was not statistically significant. The changes in lipid profile can be made useful in introducing Yoga as a lifestyle modification in individuals with increased risk to hypertension and coronary vascular disease. The incidence of atherosclerosis can also be decreased by implementing Yoga from early childhood routinely.

Limitations of the study: Confounding factors such as occupation, involvement in other activities, geographic variations and genetic factors could not be excluded.

\section{ACKNOWLEDGEMENT}

I am extremely thankful to Dr. Kalyani Sen, former HOD, Department of Physiology, Calicut Medical College; Dr. Annamma Mathew, former Professor, Department of Physiology, Calicut Medical College; and Dr. K. Parvathy, former HOD, Department of Biochemistry, Medical College, 


\section{Jemds.com}

Calicut for their encouragement and valuable help extended to me for the conduct of the study.

\section{REFERENCES}

[1] Tulpule TH and Tulpule AT. Yoga. A method of relaxation for rehabilitation after myocardial infaction. Indian Heart Journal 1980;32(1):1-7.

[2] Datar SV, Kulkarni VA. Yogic practices and cardio vascular efficiency, Yogamimamsa. 1997;32(1\&2):813.

[3] Tenghe S. Comprehensive approach for the treatment of the cardiac patients through yoga. Yoga Mimamsa 1990;29(3):33-42.

[4] Muralidhar DV, Ranganathan KV. Effect of yoga practice on Cardiac Recovery Index. Indi J of Physiology Pharmacology 1982:26(4)279-83.

[5] Manchanda R. Yoga and Coronary artery disease. AIIMS, New Delhi. Indian Heart Journal 1998;227-8.

\section{Original Research Article}

[6] Murugesan R, Govindarajulu N, Bera TK. Effect of selected yogic practices on the management of hypertension. Indian J Physiol Pharmacol 2000;44(2):207-10.

[7] Sundar S, Agarwal SK, Singh VP, et al. Role of yoga in management of essential hypertension. Acta Cardiol 1984;39(3):203-8.

[8] Brownstein AH, Dembert ML. Treatment of essential hypertension with Yoga relaxation therapy in a USAF aviator: a case report. Aviat Space Environ Med 1989;60(7):684-7.

[9] Schmidt T, Wijga A, von Zur Muhlen A, et al. Changes in cardiovascular risk factors and hormones during a comprehensive residential three month Kriya yoga training and vegetarian nutrition. Acta Physiol Scand Suppl 1997;640:158-62. 